\title{
The Comparison of the Effectiveness of Respiratory Physiotherapy Plus Myofascial Release Therapy Versus Respiratory Physiotherapy Alone on Cardiorespiratory Parameters in Patients With COVID-19
}

Sara Fereydounnia, PhD, PT, Azadeh Shadmehr, PhD, PT, Alireza Tahmasbi, MSc, PT, Raha Shams Salehi, MSc, SPT

Physical Therapy Department, School of Rehabilitation, Tehran University of Medical Sciences, Tehran, Iran

https://doi.org/10.3822/ijtmb.v14i4.697

Background: Respiratory involvement is a common consequence of COVID-19; changes in cardiorespiratory parameters of these patients during respiratory rehabilitation program are very important. Previous studies showed that myofascial release therapy (MFRT) could affect the respiratory muscle and adjunct fascia.

Purpose: The aim of this study was to evaluate the effects of MFRT techniques and respiratory physiotherapy, in comparison with respiratory physiotherapy alone, on improving cardiorespiratory parameter in patients with COVID-19.

Setting: A hospital affiliated to Tehran University of Medical Sciences in Tehran, Iran, from February to July 2021.

Participants: Fifty patients with COVID-19 participated in this study.

Research Design: A single-blind, randomized control design.

Intervention: The patients with COVID-19 randomly assigned to an intervention group who received respiratory physiotherapy combined with MFRT or a control group receiving respiratory physiotherapy alone.

Main Outcome Measure(s): Heart rate, systolic and diastolic blood pressure, respiration rate, oxygen saturation, chest expansion, and ease of breathing were assessed at baseline and after the first and third session of treatment. Dyspnea and fatigue perception and 6-minute walking were assessed at baseline and at the end of treatment. Patient's thoughts about the treatment were examined through the 4-point Likert scale.

Results: The ANOVAs found significant time effect for ease of breathing, dyspnea perception $(F=32.33, p<.01$ and $F=11.72$, $p<.01$, respectively). Also significant time by group interaction was found for chest expansion at xiphoid level ( $F=4.02, p=.02)$.
Conclusions: The present study provided evidence that both programs could result in improving ease of breathing and dyspnea perception, although the inclusion of MFR techniques into a respiratory physiotherapy program did not result in better outcomes in cardiorespiratory function of patients with COVID-19.

KEYWORDS: respiratory physiotherapy; myofascial release therapy; cardiorespiratory; COVID-19

\section{INTRODUCTION}

Coronavirus 2019 (Covid-19) was declared a pandemic on March 11, 2020 by the World Health Organization (WHO). The classic routes of infection for SARS-COV-2 are through respiratory droplets and human communication. During the first days of infection, a disease appears with mild fever, dry cough, fatigue, sputum production, and moderate-to-severe respiratory distress. ${ }^{1)}$ Approximately $14 \%$ of patients experience the severe form of Covid-19, which requires hospitalization, and 5\% require hospitalization in the intensive care unit (ICU).(2) The median interval between the onsets of symptoms to the development of dyspnea is five to eight days, and acute respiratory distress syndrome (ARDS) is $8-12$ days. (3) Depending on the severity of the disease in patients, they may require oxygen therapy, non-invasive ventilation (NIV) including continuous passive airway pressure (CPAP), and intubation and hospitalization in ICUs if no immediate positive response is observed. Patients in ICUs may experience a number of complications including dysphagia, severe weight loss, decreased muscle strength, myopathy and neuropathy, decreased joint mobility, 
inability to stand upright, impaired balance and walking, limitations in daily activities, and numerous psychological problems. ${ }^{(4,5)}$

The coronavirus could also cause mild to severe pneumonia or respiratory hypoxia. In addition, patients may be at risk for residual or developmental parenchymal damage and impaired respiratory muscle function. (5) Physiotherapists during the Covid-19 pandemic period play an important role in reducing hospitalization rates, emergency unit visits, and improving recovery of survivors. ${ }^{(6)}$ Respiratory rehabilitation is a comprehensive intervention based on patient evaluation and is not only limited to exercise training, but it is also designed to improve the physical condition of people with respiratory disease. (7) In the subacute phase, inspiratory muscle training, deep and slow breathing, diaphragmatic breathing, chest expansion, respiratory muscle mobilization, airway clearance techniques, and devices that cause positive expiratory pressure should be used, based on evaluation. A randomized clinical trial study showed a significant improvement in pulmonary function, tolerance, quality of life, and depression of elderly patients with COVID-19 after 12 sessions of respiratory physiotherapy. ${ }^{(8)}$

On the other hand, there are several evidences in pulmonary diseases like chronic obstructive pulmonary disease (COPD), that show the accessory respiratory muscles are recruited due to changes in respiratory mechanics and a compensatory adaptation occurs, so these muscles becomes short and overactive. Recently, the use of manual therapies to reduce these changes has been considered.(9) Manual therapy includes the use of techniques such as massage, myofascial release, muscle energy technique, mobilization, and joint manipulation to treat musculoskeletal or visceral systems. ${ }^{(9)}$ Studies have shown that manual therapy of the diaphragm improves its expansion and thus improves respiratory mechanics, facilitates lymph flow to the bronchial tree, and reduces airway congestion. ${ }^{(10)}$ In a study by Rocha et al., the manual diaphragm release technique improved diaphragm mobility, 6-minute walking distance, and inspiratory capacity in COPD. ${ }^{(17)}$ Myofascial release techniques have the potential to return muscle fibers to their normal length, resulting in more effective contraction. (12)

Since the COVID pandemic has had a significant impact on the physical and mental health of patients, has incurred high costs on the health care and insurance system, has affected human relations, and has demonstrated that respiratory involvement is a common consequence of this disease, changes in respiratory function and tolerance of these patients during respiratory rehabilitation programs are very important. Based on the evidence of involvement of the accessory respiratory muscles and fascia of the cervicothoracic region in people with respiratory diseases, the present study intended to investigate the effect of myofascial release on the respiratory function and tolerance of patients with Covid-19.

\section{METHODS \& MATERIALS}

\section{Study Design}

This single-blind RCT included three sessions (on three consecutive days) of interventions with three assessments (at baseline, and after the first and third session of intervention) for two parallel groups receiving both MFR therapy and respiratory physiotherapy or respiratory physiotherapy alone. This study was in accordance with the principles of the Declaration of Helsinki and was approved by the Ethics Committee of the Tehran University of Medical Sciences and the Iranian Registry of Clinical Trials (IRCT20210214050356N1). It was conducted in the one of the specialized hospitals for COVID-19 in Tehran, Iran.

\section{Participants}

Fifty patients with COVID-19 (intervention group $=25$, control group $=25$, who were receiving supplemental oxygen therapy and also Methylprednisolone) were enrolled in the present study. The aims and procedures of the study were explained to the eligible patients with COVID-19, who were asked to sign a consent form. The inclusion and exclusion criteria were checked at the enrolment stage (Table 1), and the flowchart of selecting patients for the study is shown in Figure 1. Randomization was done based on a single sequence (simple randomization) and the random number table method was used, so that the table was read from above and even numbers were considered for the control group (respiratory physiotherapy) and odd numbers for the intervention group 
TABLE 1. Selection Criteria for Patients with COVID- 19

Inclusion Criteria

- Definitive diagnosis of Covid-19 (PCR test positive)

- The absence of other acute respiratory infection at least for the late six months

- The absence of COPD or other respiratory diseases

Exclusion Criteria

- The time of initial diagnosis or onset of symptoms was 3 days or less

- New onset of arrhythmia and myocardial ischemia

- Moderate to severe heart disease (grade 3 or 4, according to the New York Heart Association)

- Ischemic or hemorrhagic stroke or neurodegenerative diseases

- Decreased level of consciousness

- Heart rate less than 40 and more than 120 beats per minutes

- Blood pressure less than 90/60 mm Hg and more than 180/90 $\mathrm{mm} \mathrm{Hg}$

- Respiratory rate of more than 40 per minutes

- Spo2 90\% or less

- Body temperature over 38 degree centigrade

- The chest X- ray or CT scan had worsen by more than $50 \%$ in the last 24 to 48 hours (Wang et al., 2020)

- Reluctance to continue treatment

- Finally discharge with personal consent

(myofascial release therapy and respiratory physiotherapy). Allocation concealment was done using sealed opaque envelopes. In this way, 50 envelopes were prepared with aluminum wrappers and each of the random sequences created was recorded on a card and the cards were placed inside the envelopes in order. Finally, the lid of the envelope was glued and all envelopes were placed inside a box. At the beginning of the study, each of the envelopes was opened in order and the assigned group of the patient was revealed.

\section{Assessments}

In the present study, all assessments and interventions were provided by a physiotherapist. During the procedure of assessment and also intervention, the physiotherapist constantly monitored the patient's symptoms, and stopped the test if the blood oxygen saturation level dropped below $85 \%$, the heart rate increased to more than 120 beats per minute, or the dyspnea increased. Also, the physiotherapist followed all personal protection protocols, including regular hand washing, and the wearing of disposable protective clothing, gloves, masks, and face shields. Therapist gloves were changed for each patient and the vibrator was disinfected for each patient. Also the patients wore masks during all of the procedures.

\section{Cardiopulmonary monitoring}

Heart rate, systolic blood pressure, diastolic blood pressure, respiration rate, and blood oxygen saturation were recorded at baseline and after the treatment in the first and third session.

\section{Chest expansion}

Chest expansion was measured at both rib and xiphoid levels. To assess expansion at the rib level, the spinous process of the fifth thoracic vertebra, the middle of the clavicular line, and the third rib space were selected as the landmarks. To assess expansion at the xiphoid level, spinous process of the 10th thoracic vertebra and xiphoid process were selected as the landmarks. Patients were in the standing position with their hands on their heads; chest circumference was measured at each level (according to the landmarks of that level) by using a tape measure. Finally the difference between the chest circumference in deep inhalation and exhalation at these levels was recorded as the chest expansion (Figure 2). ${ }^{(13)}$

\section{Ease of breathing}

The patients were taught the Visual Analogue Scale (VAS). A score of zero was given for deep, comfortable, and painless breathing, and 10 for inability to breathe deeply and feeling restriction and shortness of breath. The patients marked their perception about their breathing on the ruler according to the description given. ${ }^{(14)}$

\section{Dyspnea perception}

The Modified Borg Scale, a scale from zero to 10, was used to assess dyspnea. Zero was a sign of no dyspnea and 10 was the maximum sign of dyspnea that a person had ever felt. Dyspnea perception was assessed during a 6-minute walking test (6 MWT). ${ }^{(15)}$

\section{Fatigue perception}

The Modified Borg Scale was used to assess respiratory fatigue. Zero was a sign 


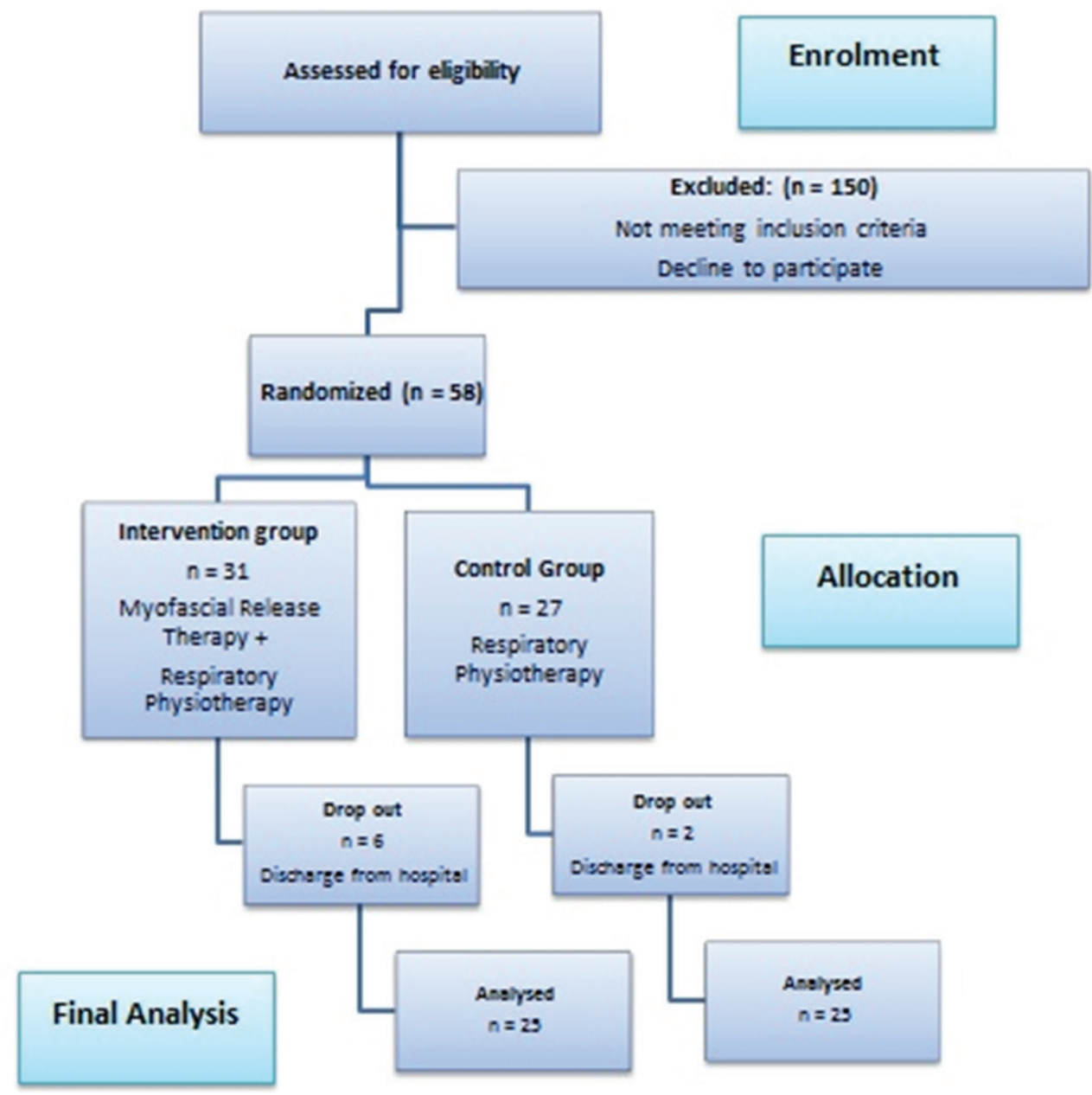

FIGURE 7. Flowchart of patients throughout the course of the study.
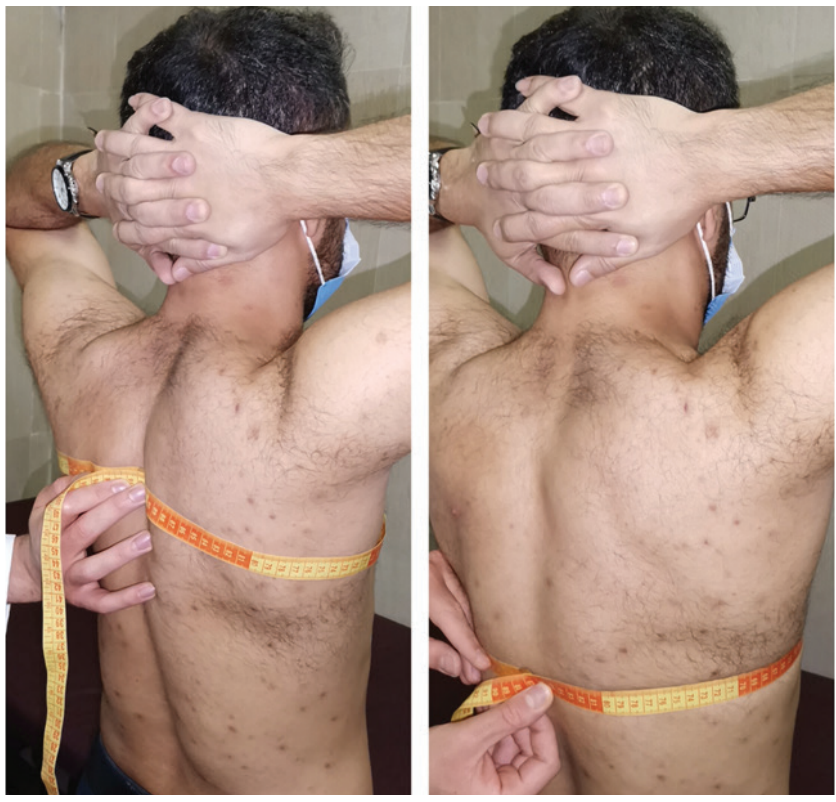

FIGURE 2. Measuring chest expansion at $\mathbf{A}: 3^{r d}$ rib level, and B: xiphoid level. of no fatigue and 10 signs of maximum fatigue that the person had ever felt. This scale has a high reproducibility when assessing fatigue during exercise (6-minute waking test). ${ }^{(15)}$ Fatigue perception was assessed during a 6-minute walking test.

\section{Six-minute walking test}

Exercise tolerance was assessed using a 6-minute walking test-the distance each patient travels in 6 minutes. This test measures the distance that the patient can walk at a comfortable speed on a smooth and firm surface in 6 minutes, and reflects the patient's ability to perform daily activities. The patient wore comfortable clothing and walking shoes. The test was performed in the corridor of the lung ward (for Covid-19 patients). The patient could slow down, stop, or rest during the test if necessary. The patient could lean against the wall, but still stand. The timer did not stop while the patient was 
resting. The predicted maximum heart rate was 120 beats per minute, because the patients with COVID-19 should not have tachycardia.

\section{Patient's thoughts about the treatment}

The patient's opinions about the treatment were examined through the 4-point Likert scale, in which the patient was asked the following four questions. The patient answered: 1) strongly disagree, 2) disagree, 3) agree, or 4) strongly agree.

1) I benefited from the treatment.

2) I breathed easier after the treatment.

3) I enjoyed receiving the treatment.

4) I recommend this treatment to other patients with Covid-19.(14)

\section{Intervention}

All interventions for all of the patients were performed by a therapist with three years of clinical experience. Depending on the group to which the patients had been allocated, they received either MFR therapy and respiratory physiotherapy or respiratory physiotherapy alone. The duration of each treatment session was approximately 45 minutes for the intervention group and approximately 20 minutes for the control group. There was a 24-hour interval between each treatment session.

\section{Respiratory Physiotherapy (included the} following)

1) Breathing training exercises: These exercises were done in two stages:

a) Patients were seated on the edge of the bed. They placed their hands behind their necks, brought their two elbows together in front of their bodies, and leaned forward. Then they straightened the trunk and at the same time abducted the shoulders and did a deep inhalation through the nose. They returned to their original position and exhaled through the nose.

b) Patients sat on the edge of the bed, raised their hands above their heads, and again inhaled deeply through their noses, then leaned forward and crossed their arms at the ankles. At the same time, they exhaled through the mouth. Both breathing exercises were repeated ten times.

2) Diaphragmatic breathing training: The patient was placed in a supine position and a light weight was placed on the anterior abdominal wall to resist the depression of the diaphragm muscle. Patients repeated diaphragmatic breathing 30 times.

3) Vibration: The Thrive 717 Vibrator Massager (made in Japan) was used over the anterior, middle, and lower lobes of the right lung and the upper and lower lobes of the left lung from the anterior view, and upper and lower lobes of both lungs from the posterior view to drain mucus for ten minutes.

4) Cough training: Patients sat on the edge of the bed. They leaned forward slightly, placed their hands on their bellies, and took a deep breath. While exhaling through the mouth, they applied a slight pressure to the abdomen and at the same time coughed two to three times with the mouth half open. This was repeated five times.

The Myofascial Release Therapy (included the following techniques)

\section{Sub-occipital release technique}

The patient was placed in the Fowler's position (the patient was seated in a semi-sitting position $\left(45^{\circ}-60^{\circ}\right)$ with knees bent). The physiotherapist placed his hand under the occiput, with his fingertips facing the ceiling, applying gentle pressure to release the tissues under his fingertips. The physiotherapist then applied a very gentle traction between the occiput and the atlas (Figure 3A). ${ }^{(9)}$

\section{Anterior cervical myofascial release technique}

The patient was in the Fowler's position. One hand of the physiotherapist was on the inferior angle of the mandible and the other hand was on the lower edge of the clavicle. A force was applied superior and medial to the mandible and inferior and lateral to the lower edge of the clavicle. The pressure was maintained until the tissue was released (became softer and more pliable) (Figure 3B). ${ }^{(9)}$

\section{Anterior thoracic and sternal myofascial release technique}

The patient was placed in the Fowler's position. The physiotherapist placed one hand under the occiput and the other on 
the sternum, so that the heel of the hand was inferior to the sternoclavicular joint. The physiotherapist applied traction to separate the fascia and the sternochondral joints, keeping the pressure in place until the tissue was released (became softer and more pliable) (Figure 3C).(9)
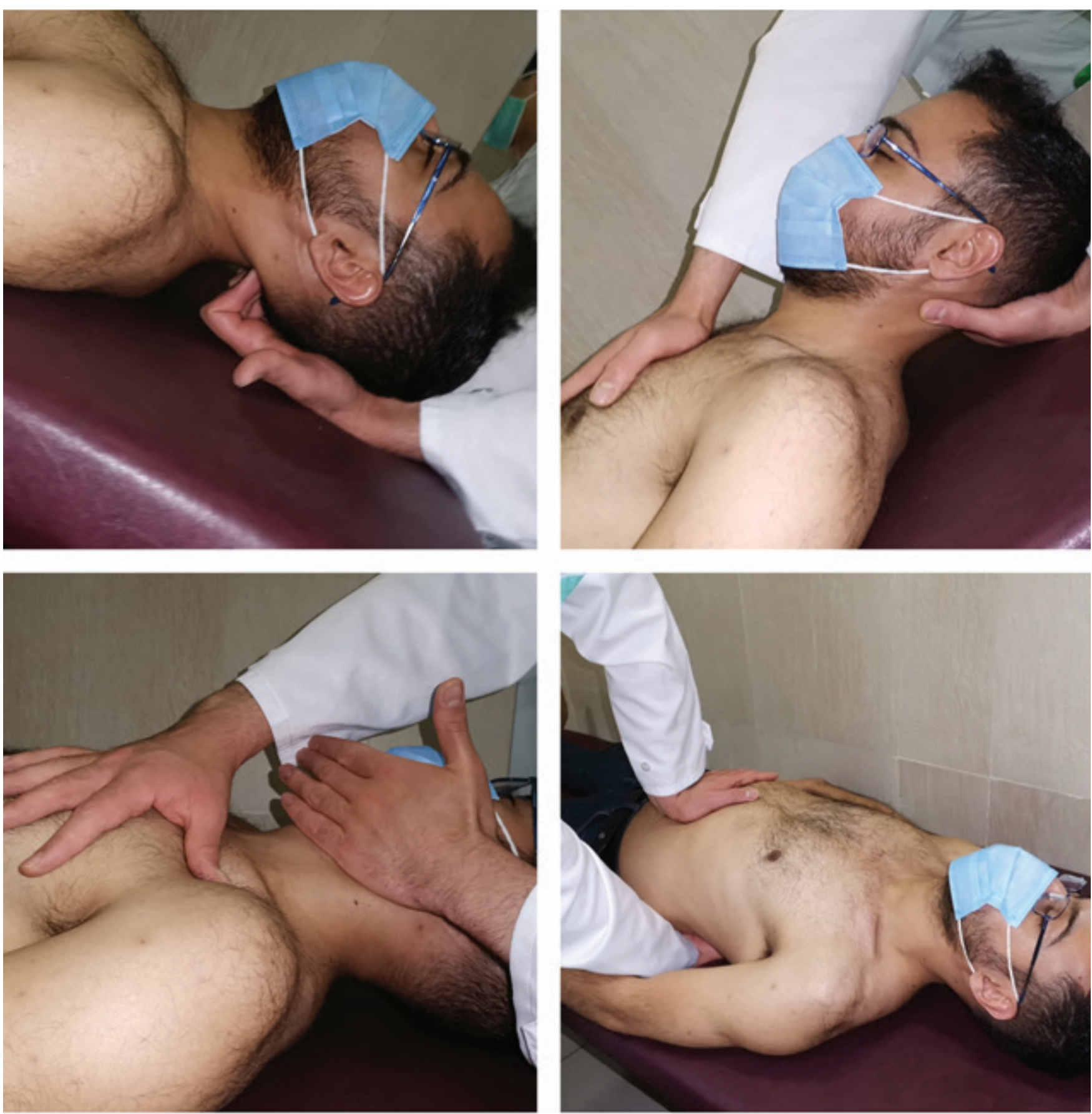

FIGURE 3. Myofascial release techniques: A: Sub-occipital release technique; B: Anterior thoracic myofascial release and sternal release technique; $\boldsymbol{C}$ : Anterior cervical myofascial release technique; and D: Diaphragm release technique. In this figure (parts $A, B$, and $C$ ), the patient is not in the Fowler's position.

\section{Diaphragm release technique} physiotherapist placed one hand on the diaphragm and the other hand under the patient's body parallel to the upper hand. Pressure was applied downward through the upper hand and was maintained until
The patient's position was supine. The 
FEREYDOUNNIA: EFFECTS OF RESPIRATORY PHYSIOTHERAPY WITH/WITHOUT MYOFASCIAL RELEASE ON CARDIORESPIRATORY PARAMETERS IN COVID PATIENTS

the tissue was released (became softer and more pliable) (Figure 3D)..13)

\section{Statistical Analysis}

Statistical analysis was performed using SPSS Statistical Software, version 17 (IBM SPSS Statistics, Armonk, NY). The Kolmogrov-Smirnov test showed a normal distribution of all the data $(p>.05)$. Baseline features between both groups were compared using independent $t$ test for continuous variables. A 3*2 repeated measured ANOVA with time (baseline, after the first session, and after the third session) as within-subjects factor and group (control or intervention) was used to calculate the changes in the outcomes, except for 6-minute walking, dyspnea, and fatigue perception. The analyses of the last three variables were performed using a 2*2 repeated measured ANOVA, because the assessments were done in two time periods (at baseline and after the third session). All of the ANOVA tests were followed by Bonferroni post hoc test. The power of the statistical tests is reported based on the "estimated power" value in the ANOVA test tables of SPSS. The frequency and percentage of levels of the 4-point Likert for patient's thoughts about the treatment were reported.

\section{RESULTS}

Baseline features between both groups were not statistically different for all variables $(p>$.05) (Table 2).

The mixed model ANOVAs revealed significant time effect for ease of breathing, dyspnea perception ( $F=32.33, p<.01$ and $F$ $=11.72, p<.01$, respectively). Also significant time by group interaction was found for chest expansion at xiphoid level $(F=4.02$, $p=.02$ ). Table 3 provides baseline and after first and third session of intervention data, as well as within-group differences.

The results of Bonferroni test showed that heart rate decreased after the first session of treatment in the intervention group (mean difference $=-3.78, p=.03$ ). The results of Bonferroni also showed that ease of breathing was improved during the sessions (first session - baseline: mean difference $=-0.41, p=.03$; third session - baseline: mean difference $=-1.38, p<.01$, third session - first session: mean difference = $-0.97, p<.01)$.
All of the participants in both groups said that they benefited from the treatment, now breathe easier, enjoyed receiving the treatment, and would recommend this treatment to other patients with COVID-19 (Table 4).

\section{DISCUSSION}

The goal of the present study was investigating the effects of MFR therapy on cardiorespiratory parameters in patients with COVID-19. Both of the intervention (MFR therapy + respiratory physiotherapy) and control (only respiratory physiotherapy) groups participated in three session of intervention. The results of the present study showed that the addition of myofascial release therapy to respiratory physiotherapy did not have significant effects on improving the cardiorespiratory parameters in patients with COVID-19. However, in both groups we observed a statistically significant decrease in VAS score for ease of breathing, and a decrease in the Borg scale for the dyspnea perception.

Given that COVID-19 is a disease that has recently been recognized and declared a pandemic, there are not many studies in the field of respiratory physiotherapy, and especially manual therapy, of these patients. Therefore, this section refers to four studies that assess the effectiveness of manual therapy techniques in chronic obstructive pulmonary disease.

Engel and Vemulpad investigated the effect of combining manual therapy with exercise on the respiratory function of normal

TABLE 2. Baseline Features of the Participants with COVID-19 (Intervention Groups: $\mathrm{N}=25$, Controls: $\mathrm{N}=25$ )

\begin{tabular}{lccccc}
\hline \multirow{2}{*}{ Variables } & \multicolumn{2}{c}{ Mean $\pm S D$} & \multirow{2}{*}{$\begin{array}{c}\text { Sig. (2- } \\
\text { tailed) }\end{array}$} \\
\cline { 2 - 3 } & Intervention & Control & & \\
\hline $\begin{array}{l}\text { Female/ } \\
\text { Male (n) }\end{array}$ & $10 / 15$ & $17 / 14$ & & \\
Age (year) & $49.44 \pm 14.78$ & $45.00 \pm 12.75$ & -1.14 & 0.26 \\
Weight (kg) & $83.08 \pm 14.84$ & $79.16 \pm 13.91$ & -0.77 & 0.45 \\
Height (cm) & $172.76 \pm 8.17$ & $170.08 \pm 8.32$ & -1.5 & 0.26 \\
BMl (Kg/m ${ }^{2}$ ) & $27.84 \pm 4.72$ & $27.54 \pm 3.62$ & -0.25 & 0.80 \\
$\begin{array}{l}\text { Smoking } \\
\text { (nonsmoker/ } \\
\text { smoker) }\end{array}$ & $20 / 5$ & $23 / 2$ & & \\
\hline
\end{tabular}


FEREYDOUNNIA: EFFECTS OF RESPIRATORY PHYSIOTHERAPY WITH/WITHOUT MYOFASCIAL RELEASE ON CARDIORESPIRATORY PARAMETERS IN COVID PATIENTS

TABLE 3. Test Statistics for the Repeated Measures ANOVA Main Effects of Time of Assessment, Group and Their Interaction for the Variables of the Study (Intervention Groups: $\mathrm{N}=25$, Controls: $\mathrm{N}=25$ )

\begin{tabular}{|c|c|c|c|c|c|c|c|}
\hline \multirow[t]{2}{*}{ Variables } & \multirow[t]{2}{*}{ Groups } & \multicolumn{3}{|c|}{ Mean $\pm S D$} & \multirow{2}{*}{$\begin{array}{c}\text { Time } \\
\text { Effect } \\
\begin{array}{c}F \\
\text { Pvalue } \\
\text { Power }\end{array}\end{array}$} & \multirow{2}{*}{$\begin{array}{c}\text { Group } \\
\text { Effect } \\
\begin{array}{c}F \\
\text { P value } \\
\text { Power }\end{array}\end{array}$} & \multirow{2}{*}{$\begin{array}{c}\text { Timea } \\
\text { Group } \\
\text { Effect } \\
\text { F } \\
\text { P value } \\
\text { Power }\end{array}$} \\
\hline & & $\begin{array}{c}\text { After } \\
\text { (3rd session) }\end{array}$ & $\begin{array}{c}\text { After } \\
\left(7^{s t} \text { session) }\right.\end{array}$ & Baseline & & & \\
\hline \multirow[t]{2}{*}{ Heart Rate (bpm) } & Intervention & $74.96 \pm 14.98$ & $76.96 \pm 13.49$ & $81.40 \pm 13.65$ & 2.57 & 0.14 & 0.95 \\
\hline & Control & $79.08 \pm 12.14$ & $77.24 \pm 12.24$ & $80.36 \pm 12.83$ & $\begin{array}{c}.08 \\
0.50\end{array}$ & $\begin{array}{c}.71 \\
0.06\end{array}$ & $\begin{array}{c}.39 \\
0.21\end{array}$ \\
\hline \multirow{2}{*}{$\begin{array}{l}\text { Systolic Blood } \\
\text { Pressure (mm Hg) }\end{array}$} & Intervention & $123.16 \pm 13.20$ & $124.60 \pm 13.06$ & $122.52 \pm 13.85$ & 0.92 & 0.00 & 0.03 \\
\hline & Control & $122.60 \pm 10.36$ & $124.20 \pm 12.34$ & $121.52 \pm 13.85$ & 0.20 & 0.05 & 0.05 \\
\hline \multirow{2}{*}{$\begin{array}{l}\text { Diastolic Blood } \\
\text { Pressure (mm Hg) }\end{array}$} & Intervention & $78.08 \pm 10.07$ & $77.68 \pm 11.32$ & $75.80 \pm 11.89$ & 2.31 & 0.05 & 0.19 \\
\hline & Control & $78.44 \pm 7.08$ & $79.00 \pm 9.34$ & $75.72 \pm 10.96$ & 0.45 & $\begin{array}{l}.85 \\
0.05\end{array}$ & 0.07 \\
\hline \multirow[t]{2}{*}{ Respiratory Rate } & Intervention & $18.40 \pm 4.72$ & $18.48 \pm 4.72$ & $18.16 \pm 5.09$ & 0.63 & 0.02 & $\begin{array}{c}0.94 \\
39\end{array}$ \\
\hline & Control & $17.36 \pm 4.13$ & $18.16 \pm 5.82$ & $20.16 \pm 13.19$ & 0.15 & 0.05 & 0.21 \\
\hline \multirow[t]{2}{*}{$\mathrm{SpO}_{2}(\%)$} & Intervention & $94.96 \pm 2.46$ & $94.92 \pm 2.22$ & $94.88 \pm 1.92$ & $\begin{array}{c}1.73 \\
.18\end{array}$ & $\begin{array}{c}1.24 \\
.27\end{array}$ & $\begin{array}{l}1.31 \\
.27\end{array}$ \\
\hline & Control & $94.96 \pm 1.95$ & $94.08 \pm 2.64$ & $94.04 \pm 1.59$ & 0.35 & 0.19 & 0.28 \\
\hline \multirow[t]{2}{*}{ CE at $3^{\text {rd }}$ rib level $(\mathrm{cm})$} & Intervention & $5.60 \pm 3.24$ & $5.34 \pm 3.06$ & $5.20 \pm 2.40$ & 1.66 & 0.17 & 0.17 \\
\hline & Control & $5.27 \pm 2.54$ & $4.94 \pm 2.68$ & $5.02 \pm 2.27$ & 0.34 & 0.07 & $\begin{array}{l}.84 \\
0.08\end{array}$ \\
\hline \multirow{2}{*}{$\begin{array}{l}\text { CE at Xiphoid level } \\
(\mathrm{cm})\end{array}$} & Intervention & $6.46 \pm 4.25$ & $5.70 \pm 3.27$ & $5.66 \pm 2.75$ & 1.21 & 0.07 & 4.02 \\
\hline & Control & $5.50 \pm 2.35$ & $5.67 \pm 2.68$ & $5.81 \pm 2.83$ & $\begin{array}{c}.30 \\
0.26\end{array}$ & $\begin{array}{c}.80 \\
0.06\end{array}$ & $\begin{array}{l}\mathbf{. 0 2}^{\mathbf{a}} \\
0.71\end{array}$ \\
\hline \multirow[t]{2}{*}{$\begin{array}{l}\text { Ease of Breathing } \\
\text { (VAS) }\end{array}$} & Intervention & $0.84 \pm 0.87$ & $1.58 \pm 1.33$ & $2.16 \pm 1.73$ & $\begin{array}{l}32.33 \\
<.01^{a}\end{array}$ & $\begin{array}{c}2.59 \\
.11\end{array}$ & $\begin{array}{c}0.85 \\
43\end{array}$ \\
\hline & Control & $1.35 \pm 1.59$ & $2.55 \pm 2.25$ & $2.80 \pm 2.13$ & 1.00 & 0.35 & 0.19 \\
\hline \multirow[t]{2}{*}{$\begin{array}{l}\text { 6- min Walking Test } \\
\text { (m) }\end{array}$} & Intervention & $243.64 \pm 8.64$ & - & $256.17 \pm 77.29$ & $\begin{array}{l}0.97 \\
.33\end{array}$ & $\begin{array}{c}2.81 \\
.10\end{array}$ & $\begin{array}{c}0.60 \\
.44\end{array}$ \\
\hline & Control & $268.05 \pm 75.39$ & - & $264.80 \pm 74.66$ & 0.16 & 0.38 & 0.12 \\
\hline \multirow[t]{2}{*}{$\begin{array}{l}\text { Dyspnea Perception } \\
\text { (Borg 0-10) }\end{array}$} & Intervention & $1.94 \pm 1.77$ & - & $2.44 \pm 1.83$ & $\begin{array}{l}11.72 \\
<.01^{a}\end{array}$ & $\begin{array}{c}0.03 \\
.87\end{array}$ & $\begin{array}{c}1.99 \\
.16\end{array}$ \\
\hline & Control & $1.68 \pm 2.15$ & - & $2.88 \pm 2.75$ & 0.92 & 0.05 & 0.28 \\
\hline \multirow{2}{*}{$\begin{array}{l}\text { Fatigue Perception } \\
\text { (Borg 0-10) }\end{array}$} & Intervention & $2.32 \pm 1.89$ & - & $2.76 \pm 2.20$ & 2.54 & 0.09 & 0.04 \\
\hline & Control & $2.12 \pm 2.18$ & - & $2.76 \pm 2.53$ & 0.34 & 0.06 & 0.05 \\
\hline
\end{tabular}

andicates significant result $(p<.05)$.

bpm = beats per minute; CE = chest expansion; VAS = visual analogue scale.

individuals. Forced Vital Capacity (FVC) and Forced Expiratory Volume during the first second (FEV1) in 20 healthy non-smokers before and after three interventions: exercise alone, manual chiropractic therapy (alone), and manual therapy following exercise. Participants underwent six sessions of intervention during four weeks. The results of their study showed that manual therapy has a potential beneficial effect on respiratory function in healthy individuals. The study also showed that manual therapy can, to some extent, overcome the short-term respiratory resistance caused by exercise. In the exercise therapy group alone there was a decrease in FVC and FEV 1 , while in the combined group there was an increase in the values of these two parameters. ${ }^{(16)}$ It is possible that the administration of manual therapy to the cervical 
FEREYDOUNNIA: EFFECTS OF RESPIRATORY PHYSIOTHERAPY WITH/WITHOUT MYOFASCIAL RELEASE ON CARDIORESPIRATORY PARAMETERS IN COVID PATIENTS

TABLE 4. Patients' Thoughts About the Treatment (Intervention Groups: $N=25$, Controls: $N=25$ )

\begin{tabular}{|c|c|c|c|c|c|}
\hline & Groups & $\begin{array}{c}\text { Strongly } \\
\text { Disagree } \\
n(\%)\end{array}$ & $\begin{array}{l}\text { Disagree } \\
n(\%)\end{array}$ & $\begin{array}{l}\text { Agree } \\
n(\%)\end{array}$ & $\begin{array}{c}\text { Strongly } \\
\text { Agree } \\
n(\%)\end{array}$ \\
\hline \multirow[t]{2}{*}{ I benefited from the treatment } & Intervention & $\mathrm{O}(0)$ & $\mathrm{O}(0)$ & $6(24)$ & $19(76)$ \\
\hline & Control & $\mathrm{O}(0)$ & $\mathrm{O}(0)$ & $8(32)$ & $17(68)$ \\
\hline \multirow[t]{2}{*}{ I breathed more easily after the treatment } & Intervention & $\mathrm{O}(0)$ & $\mathrm{O}(0)$ & $9(36)$ & $16(64)$ \\
\hline & Control & $\mathrm{O}(0)$ & $\mathrm{O}(0)$ & $12(48)$ & $13(52)$ \\
\hline \multirow[t]{2}{*}{ I enjoyed receiving the treatment } & Intervention & $\mathrm{O}(0)$ & $\mathrm{O}(0)$ & $12(48)$ & $13(52)$ \\
\hline & Control & $\mathrm{O}(0)$ & $\mathrm{O}(0)$ & $12(48)$ & $13(52)$ \\
\hline \multirow{2}{*}{$\begin{array}{l}\text { I would recommend this treatment to other } \\
\text { patients with COVID-19 }\end{array}$} & Intervention & $\mathrm{O}(0)$ & $\mathrm{O}(0)$ & $6(24)$ & 19 (76) \\
\hline & Control & $\mathrm{O}(0)$ & $\mathrm{O}(0)$ & $6(24)$ & 19 (76) \\
\hline
\end{tabular}

and thoracic regions before exercising regulates the autonomic nerve supply to the respiratory muscles. ${ }^{(17)}$ This may simply permit a short-term increase in respiratory function that creates additional capacity, which then overrides the negative effect of exercise.(16) Therefore, it's possible that these techniques were helpful for reduction of dyspnea perception in our study.

Lopez-de-Uraide-Villanueva et al. examined whether addition of manual therapy and exercise therapy protocol to the respiratory muscle training program was more effective in improving maximal respiratory pressure than the respiratory muscle training program alone. ${ }^{(18)}$ All participants received 12 training sessions, two days a week for six weeks. The main measurements included maximal inspiratory pressure, FHP measurements, and thoracic kyphosis at baseline and after treatment. The results showed that respiratory muscle training with manual therapy and exercise therapy was more effective than respiratory muscle training alone in improving FHP and maximal respiratory pressure in patients with asthma. This result can be explained biomechanically by the decrease in forward head posture, which places the accessory neck inspiratory muscles in an advantageous position in their length-tension curve, increasing their ability to generate force. (18) Accordingly, we hypothesized that tissues that were released in our study are responsible for increasing in ease of breathing due to better ability for force generation.

Balbas-Alvares et al. showed that the inspiratory muscle training protocol in combination with manual therapy and exercise had greater effects on improving maximal inspiratory pressure in healthy smokers than the inspiratory muscle training protocol alone. In addition, both groups experienced changes in maximal inspiratory pressure, but no change in lung function was observed.(10)

Galletti et al. showed that, in patients with COPD, manual therapy (with or without pulmonary rehabilitation) improved functional training capacity, but had no effect on lung function or Health Related Quality of Life (HRQL).(19)

Although these studies differ significantly from ours in terms of study design and target group, it seems that more treatment sessions may be effective in achieving better results. In addition, in the first three studies, participants underwent the standard walking treadmill program with adjustable speed, inclination, and duration (six sessions, over a period of four weeks),(16) therapeutic exercise therapy at home (12 sessions, over a period of six weeks), ${ }^{(18)}$ and motor control exercises to improve the strength and endurance of the cervicothoracic muscles (eight sessions, over a period of four weeks).(10)

On the other hand, although Hondras and colleagues in a review study showed that there was still insufficient evidence for the use of manual therapies in patients with asthma(20) and the results of our study also lacked evidence for the effectiveness of MFRT, Pepino et al. (21) in a review study stated that the use of manual techniques seems to be beneficial in children with respiratory diseases. Chiropractic, osteopathy and massage are the most commonly used interventions.

Rocha et al. showed that the manual diaphragm release technique improves 
diaphragm mobility, exercise capacity, and respiratory capacity in individuals with obstructive pulmonary disease. (11) Our study used four myofascial release techniques, but in general they failed to make a significant improvement over the control group in improving cardiorespiratory parameters. It is possible that adaptive muscle changes have occurred in people with obstructive diseases over time, but in COVID patients this change in respiratory muscle biomechanics has not yet occurred, so these techniques were not effective enough for these patients with the dosage we used. It may have a significant effect on cardiorespiratory parameters by increasing the number and duration of sessions.

Various abnormalities in pulmonary function, physical function, and psychology have been reported in patients with Covid-19. Liu et al. examined the effects of six-week respiratory rehabilitation on respiratory function, quality of life, mobility, and psychological function in elderly patients with Covid-19. The results showed that six weeks of pulmonary rehabilitation could improve respiratory function, quality of life, and anxiety in elderly patients with Covid-19, but only slightly improved depression in the elderly. (22) In spite of our investigation, 6-minute walk distance test improved significantly in that study. It may be due to more extended period of intervention plus more focus on pulmonary muscle exercises which enabled patients to tolerate longer distances. As the results of our study showed, respiratory physiotherapy had the ability to improve ease of breathing, dyspnea perception, and chest expansion at the xiphoid level. Also, according to the Likert scale, all patients were satisfied with this treatment and felt that they were breathing better, and they intended to recommend it to other patients with COVID-19.

One of our main limitations in this study was the selection of patients according to the selection criteria (Table 1) so that, out of 150 patients evaluated, only 58 were eligible to participate in the study. In addition, due to the fact that this study was performed in the hospitalization phase of patients, it was not possible to study the long-term results and follow-up, and treatment and evaluations were limited to three sessions. The authors suggest performing this study for outpatients with COVID-19 and other stages of the disease, as well as long-term follow-up.

\section{CONCLUSION}

Addition of myofascial release to respiratory physiotherapy program did not make significant changes in the recovery of patients with COVID-19. Respiratory physiotherapy may not alter heart rate, blood pressure, respiratory rate, $\mathrm{SpO}_{2}$, distance traveled in the 6-minute walking test, and fatigue perception, but during treatment sessions there were apparent improvements in chest expansion at xiphoid level, dyspnea perception, and patients were subjectively satisfied with treatment outcomes. Therefore, it is recommended to pay attention to respiratory physiotherapy of these patients, along with other medical treatments, and to include them in treatment protocols

\section{ACKNOWLEDGMENTS}

We are immensely grateful to the patients who participated in this study. This study was funded and supported by Tehran University of Medical Sciences (TUMS); Grant.no.99-3-103-51023.

\section{CONFLICT OF INTEREST NOTIFICATION}

The authors declare there are no conflicts of interest.

\section{COPYRIGHT}

Published under the CreativeCommons Attribution-NonCommercial-NoDerivs 3.0 License.

\section{REFERENCES}

1. Battaglini D, Robba C, Caiffa S, Ball L, Brunetti I, Loconte $\mathrm{M}$, et al. Chest physiotherapy: an important adjuvant in critically ill mechanically ventilated patients with COVID-19. Resp Physiol Neurobiol. 2020:103529.

2. Thomas P, Baldwin C, Bissett B, Boden I, Gosselink R, Granger CL, et al. Physiotherapy management for COVID-19 in the acute hospital setting: clinical practice recommendations. J Physiother. 2020;66(2):73-82.

3. Mohamed AA, Alawna M. Role of increasing the aerobic capacity on improving the function of immune and respiratory systems in patients with coronavirus (COVID-19): a review. Diabetes Metab Syndrome: Clin Res Rev. 2020;14(4): 489-496. 


\section{FEREYDOUNNIA: EFFECTS OF RESPIRATORY PHYSIOTHERAPY WITH/WITHOUT MYOFASCIAL}

RELEASE ON CARDIORESPIRATORY PARAMETERS IN COVID PATIENTS

4. Kiekens C, Boldrini P, Andreoli A, Avesani R, Gamna $\mathrm{F}$, Grandi $\mathrm{M}$, et al. Rehabilitation and respiratory management in the acute and early post-acute phase."Instant paper from the field" on rehabilitation answers to the COVID-19 emergency. Eur J Phys Rehab Med. 2020.

5. Vitacca M, Lazzeri M, Guffanti E, Frigerio P, D'Abrosca F, Gianola S, et al. An Italian consensus on pulmonary rehabilitation in COVID-19 patients recovering from acute respiratory failure: results of a Delphi process. Monaldi Arch Chest Dis. 2020;90:1444.

6. Falvey JR, Krafft C, Kornetti D. The essential role of home-and community-based physical therapists during the COVID-19 pandemic. Phys Ther. 2020;100(7):1058-1061.

7. Wang TJ, Chau B, Lui M, Lam G-T, Lin N, Humbert S. PM\&R and pulmonary rehabilitation for COVID-19. Am J Phys Med Rehab. 2020;99(9):769-774.

8. Sheehy LM. Considerations for postacute rehabilitation for survivors of COVID-19. JMIR Pub Health Surveillance. 2020;6(2):e19462.

9. Cruz-Montecinos C, Godoy-Olave D, ContrerasBriceño FA, Gutierrez P, Torres-Castro R, MinetVenegas $L$, et al. The immediate effect of soft tissue manual therapy intervention on lung function in severe chronic obstructive pulmonary disease. Int J Chronic Obstr Pulmon Dis. 2017;12:691.

10. Balbás-Álvarez L, Candelas-Fernández P, Del Corral T, La Touche R, López-de-Uralde-Villanueva I. Effect of manual therapy, motor control exercise, and inspiratory muscle training on maximum inspiratory pressure and postural measures in moderate smokers: a randomized controlled trial. J Manip Physiol Ther. 2018;41(5):372-382.

11. Rocha T, Souza H, Brandao DC, Rattes C, Ribeiro L, Campos SL, et al. The manual diaphragm release technique improves diaphragmatic mobility, inspiratory capacity and exercise capacity in people with chronic obstructive pulmonary disease: a randomised trial. J Physiother. 2015;61(4): 182-189.

12. Marizeiro DF, Florêncio ACL, Nunes ACL, Campos NG, de Paula Lima PO. Immediate effects of diaphragmatic myofascial release on the physical and functional outcomes in sedentary women: a randomized placebo-controlled trial. J Bodywk Move Ther. 2018;22(4):924-929.

13. Nair A, Alaparthi GK, Krishnan S, Rai S, Anand R, Acharya $\mathrm{V}$, et al. Comparison of diaphragmatic stretch technique and manual diaphragm release technique on diaphragmatic excursion in chronic obstructive pulmonary disease: a randomized crossover trial. Pulmonary Med. 2019;2019
14. Yelvar GDY, Çirak Y, Demir YP, Dalkilinç M, Bozkurt B. Immediate effect of manual therapy on respiratory functions and inspiratory muscle strength in patients with COPD. Int J Chronic Obstr Pulmon Dis. 2016;11:1353.

15. Gomes TT, Schujmann DS, Fu C. Rehabilitation through virtual reality: physical activity of patients admitted to the intensive care unit. Revista Brasileira de terapia intensiva. 2019;31(4): 456-463.

16. Engel RM, Vemulpad S. The effect of combining manual therapy with exercise on the respiratory function of normal individuals: a randomized control trial. J Manip Physiol Ther. 2007;30(7): 509-513.

17. Engel RM, Vemulpad SR, Beath K. Short-term effects of a course of manual therapy and exercise in people with moderate chronic obstructive pulmonary disease: a preliminary clinical trial. J Manip Physiol Ther. 2013;36(8):490-496.

18. López-de-Uralde-Villanueva I, Candelas-Fernández P, de-Diego-Cano B, Mínguez-Calzada O, Del Corral T. The effectiveness of combining inspiratory muscle training with manual therapy and a therapeutic exercise program on maximum inspiratory pressure in adults with asthma: a randomized clinical trial. Clin Rehab. 2018;32(6): $752-765$.

19. Galletti J, Mcheileh G, Hahne A, Lee AL. The clinical effects of manipulative therapy in people with chronic obstructive pulmonary disease. J Alt Complement Med. 2018;24(7):677-683.

20. Hondras MA, Linde K, Jones AP. Manual therapy for asthma. Cochrane Database System Rev. 2002(3).

21. Pepino VC, Ribeiro JD, de Oliveira Ribeiro MA, de Noronha M, Mezzacappa MA, Schivinski CIS. Manual therapy for childhood respiratory disease: a systematic review. J Manip Physiol Ther. 2013;36(1):57-65.

22. Liu K, Zhang W, Yang Y, Zhang J, Li Y, Chen Y. Respiratory rehabilitation in elderly patients with COVID-19: A randomized controlled study. Complement Ther Clin Pract. 2020;39:101166.

Corresponding author: Azadeh Shadmehr, Ph.D, PT, Physical Therapy Department, School of Rehabilitation, Tehran University of Medical Sciences, PicheShemiran, Enghelab Street, Tehran, Iran 1489-65111

E-mail: shadmehr@tums.ac.ir 